\title{
Analisis Pengaruh Dukungan Selebriti, Desain Kemasan, Media Sosial Terhadap Keputusan Pembelian Di Kepulauan Riau
}

\author{
Fitriana Aidnilla Sinambela, S.Tr., MM', Dr. Antony Sentoso ${ }^{2}$ \\ Fakultas Ekonomi \\ Program Magister Manajemen, Universitas Internasional Batam \\ fitrianaaidnillas@gmail.com
}

\begin{abstract}
ABSTRAK
Pada penelitian ini penulis ingin mengetahui bagaimana pengaruh variabel dukungan selebriti, desain kemasan, media sosial terhadap keputusan pembelian di Kepuluan Riau. Setelah kuesioner terkumpul data yang dapat dipakai sebanyak 410, hasil outlier sebanyak 2 sehingga data yang dapat dipakai untuk mengolah data sebanyak 408 responden. Kemudian data yang akan dijadikan sampel adalah mahasiwa/i universitas swasta di kepulauan Riau. Penulis menggunakan teknik Non probability sampling dimana pemilihan responden tidak mempunyai unsur yang sama sehingga terpilih menjadi responden sedangkan metode yang dipakai adalah purposive sampling. Hasil SPSS akan membantu menyimpulkan adanya hubungan yang signifikan dari beberapa variabel yang diteliti. Hasil penelitian secara simultan dan parsial menyimpulkan bahwa dukungan selebriti, desain kemasan, media sosial berpengaruh signifikan terhadap keputusan pembelian di Kepulauan Riau.
\end{abstract}

Keywords: Dukungan selebriti; Desain kemasan ; Media Sosial; Keputusan Pembelian

\begin{abstract}
ABSTRAK
In this research the writer wanted to find out how the influence of Celebrity Endorsement, Design Packaging, Socia Medial on purchasing decision in Kepulauan Riau. This research applied survey method by distributing questionnaires to 410 respondents. After the questionnaire was collected, the data could be used were 408 since there were 2 outlier that could not be used. so that data that could be used to process data were 408 respondents. Respondents used as were are students of private universities in Kepulauan Riau, The technique used by the authors is Non probability sampling where the selection of respondents doesn't have the same elements so that they are selected as a respondents while the method used is purposive sampling. After the results of the respondents were collected, then the researchers conducted the data testing using SPSS software. The results of the spss conclude there is a significant relation of several variables that have been studied. The SPSS results will help infer a significant relationship between the variables studied. The results of the study simultaneously and partially concluded that Celebrity Endorsement, Design Packaging, Social Media significantly influence purchasing decisions in Kepulauan Riau.
\end{abstract}

Keywords: Celebrity Endorsement, Design Packaging, Social Media, Purchase Decision 


\section{Pendahuluan 1.1. Latar Belakang}

Diera masa kini, ekonomi yang sangat kompetitif dikarenakan pembeli yang sangat rasional dihadapkan dengan pilihan yang melimpah dan esensi pemasaran strategis. Gaya hidup yang berubah dari masa kemasa akan bergerak dinamis. Semakin meningkatnya keragaman produk dan persaingan di pasar barang dan jasa telah menentukan laju pertumbuhan dalam jumlah iklan. Meski diakui berkurang efektifitas selama beberapa tahun terakhir, iklan tetap menjadi metode promosi penjualan yang paling disukai. Akibatnya tantangan untuk pengiklan adalah mengeksplorasi setiap kemungkinan cara membuat iklan lebih terlihat menarik dan pantas untuk konsumen.

Penggunaan selebriti dalam iklan adalah salah satu strategi yang baru terjadi dari banyak merek produk / jasa, tujuan penggunaan tersebut mungkin untuk mendapatkan perhatian dan tujuan mengingat. Dukungan selebriti adalah strategi komunikasi pemasaran umum untuk membangun produk merek/jasa. Pengiklan percaya bahwa penggunaan selebritis mempengaruhi keefektifan iklan.

Perusahaan menentukan endorser yang cocok atau memenuhi syarat untuk memberikan informasi pesan kepada konsumen, selanjutnya selebriti endorser tersebut dapat berperan sebagai opinion leader dan diharapkan dapat memberikan dampak kesadaran masyarakat untuk minat terhadap produk. Kasus mahalnya dukungan selebriti, perusahaan rela mengeluarkan dana yang sangat besar untuk melakukan pemasaran produk. Bisa dilihat salah satu artis yaitu aktor sekaligus presenter Raffi Ahmad dikabarkan menjadi salah satu seleb dengan tari endorse tertinggi. Bahkan Anak istrinya pun turut menjadi satu kesatuan untuk endorsement barang dan juga paid promote. Harga paid promote sekitar Rp 20 juta hingga Rp 27 Juta untuk sehari (otomatis) untuk Instagram foto yakni sekitar Rp 40 - Rp 60 juta dan berjangka 1 bulan sedangkan instragram video yakni Rp 60 juta hingga Rp 85 juta berjangka 3 bulan. Instagram live yakni Rp 100 juta hinga Rp 175 juta hanya untuk durasi per 1 menit lalu Instagram tv sekitar Rp 125 juta untuk 1 bulan dandurasi 10 menit. (Sumber : https://www.cnbcindonesia.com)

Selain dukungan selebriti, desain kemasan merupakan faktor lain terjadinya keputusan pembelian. Desain atau kerangka bentuk produk yang bagus akan mempengaruhi konsumen ke suatu produk. Diantara beberapa faktor mempengaruhi keputusan pembelian konsumen, kemasan produk telah menjadi pelengkap untuk membedakan barang, menarik perhatian konsumen dan mendorong mereka untuk membeli produk tertentu. Produk dengan desain kemasan yang unik akan menarik perhatian konsumen karena dapat menjadi pembeda antara produk satu dengan produk lainnya. Perusahaan antusias dalam memproduksi produk agar terlihat unggul dan salah satunya mengemas produk dengan kemasan yang unik dan bermanfaat pastinya. Kemasan digunakan untuk lebih banyak pengiriman mudah, perlindungan dan tempat produk.

Media sosial merupakan salah satu iklan yang banyak dilihat masyarakat, di zaman sekarang masyarakat tidak lepas dari smartphone karena smartphone adalah sumber alat informasi yang dipergunakan ketika mencari informasi/kebutuhan. Aplikasi semakin banyak bermunculan dimulai dari facebook, instagaram, twitte, youtube dan bigo live yang terakhir ini. Namun, Instagram tetap menjadi dominasi peminat terbanyak dari masyarakat karena selain masyarakat bisa update 
tentang kehidupan sosial mereka disela sela itulah iklan mulai bermunculan.

Keputusan pembelian dapat terjadi karena adanya daya minat / Tarik seseorang untuk membeli. Adanya dorongan dari dukungan selebriti yaitu artis mempunyai daya Tarik untuk promosi ke masyarakat. Desain kemasan yang baik dan efisien membuat daya Tarik masyarakat untuk mencoba produk tersebut dan media sosial yang sering mempromosikan produk sehingga membuat rasa penasaran masyarakt untuk mencoba produk tersebut.

\subsection{Pertanyaan Penelitian}

a. Bagaimana pengaruh dukungan selebriti terhadap keputusan pembelian di Kepulauan Riau?

b. Bagaimana pengaruh Desain Kemasan terhadap keputusan pembelian di Kepulauan Riau ?

c. Bagaimana pengaruh Media Sosial terhadap keputusan pembelian di Kepulauan Riau?

\subsection{Tujuan dan Manfaat Penelitian \\ 1.3.1. Tujuan Penelitian}

a. Untuk mengetahui apakah Dukungan Selebriti berpengaruh positif terhadap keputusan pembelian di Kepulauan Riau ?

b. Untuk mengetahui apakah Desain kemasan berpengaruh positif terhadap keputusan pembelian di Kepulauan Riau?

c. Untuk mengetahui apakah Media Sosial berpengaruh positif terhadap keputusan pembelian di Kepulauan Riau?

\subsubsection{Manfaat Penelitian}

Penelitian ini diharapkan dapat menjadi pertimbangan bagi manajemen perusahaan dalam mempromosikan produk, selain itu penelitian ini diharapkan dapat dimanfaatkan sebagai bahan referensi penelitian dimasa yang akan datang.

\section{Literature Review \\ 2.1. Dukungan Selebriti}

Pendukung iklan atau juga yang dikenal sebagai bintang iklan yang membawahi produk yang diiklankan (Zahra, 2018). Tokoh yang dikenal masyarakat karena prestasinya didalam bidang - bidang yang berbeda dari golongan yang didukung (Andrianto, 2016).

\subsection{Desain Kemasan}

Bagian atribut yang berhubungan dengan produk tetapi bukan bagian dari fisik produk itu sendiri (Resmi, 2015). Wadah produk yang meliputi penampilan fisik wadah tersebut termasuk desain, warna, pelabelan, bentuk dan bahan yang digunakan. Bagian integral dari memproyeksikan citra merek, yang kadang - kadang dirancang untuk menyampaikan gambar berkualitas tinggi disaat yang lain menandakan harga yang terjangkau(Ahmad, 2012).

\subsection{Media Sosial}

Media Interaksi sosial dengan menggunakan Teknik penerbitan agar terlihat mudah diakses dan diukur. Aplikasi online, sarana dan media yang ditunjukan untuk memfasilitasi interaksi, kolaborasi dan sharing materi (Anwar, 2018). Sarana konsumen agar dapat berbagi pesan, gambar, audio dan video informasi antara konsumen dengan yang lainnya baik perusahaan atau sebaliknya (Budiatmo, 2018).

\subsection{Model Penelitian}

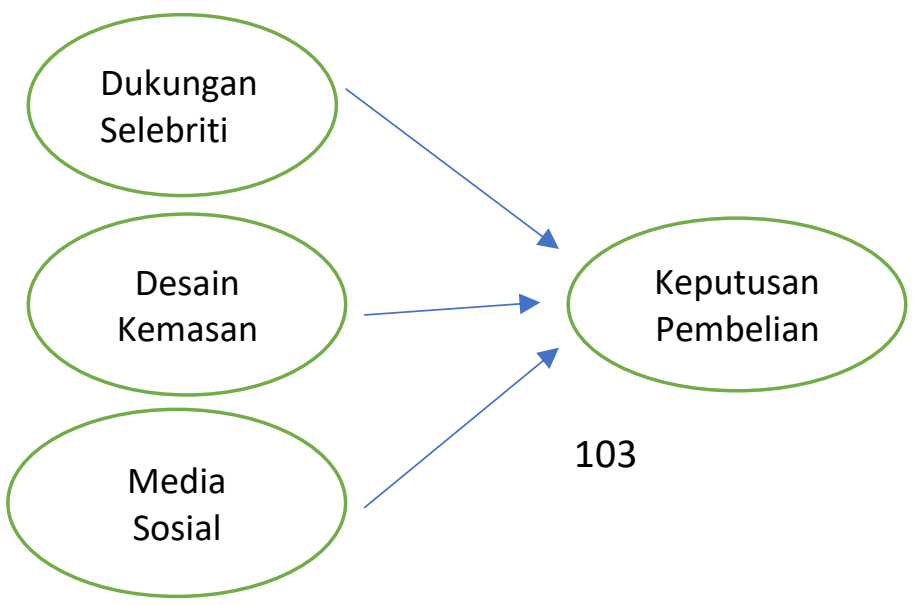


Sumber : Resmi, Wismiarsi (2015)

Ifeanyichukwu (2016)

\section{Metode Penelitian}

\subsection{Rancangan Penelitian}

Penelitian ini menggunakan pendekatan kuantitatif. Semua data diambil berdasarkan persepsi mahasiswa/I untuk mencari pengaruhnya dari variable bebas pada terikat. Peneliti menentukan pengambilan sampel dengan Teknik Non Probability sampling dan Teknik sampel Sampling purposive (Sugiyono, 2016).

\subsection{Objek Penelitian}

Kepulauan Riau menjadi tempat pilihan peneliti, populasinya adalah mahasiswa/I universitas swasta yang berada diwilayah Kepulauan Riau terdaftar di (forlap.risetdikti.go.id ) dengan jumlah sampel 394 orang menggunakan perhitungan rumus slovin.

\subsection{Definisi Operasional Variabel}

\subsubsection{Dukungan selebriti}

Dukungan Selebriti adalah icon atau bisa disebut orang yang mengiklankan produk agar dapat mempengaruhi masyarakat untuk membuat keputusan membeli produk tersebut. Celebrity yang mempunyai nama dan perilaku baik menjadi incaran dari perusahaan, perusahaan akan rela membayar mahal untuk mempromosikan produk mereka.

\subsubsection{Desain Kemasan}

Produk pasti membutuhkan desain kemasan karena kemasan dapat mempengaruhi daya Tarik I minat masyarakat untuk membeli produk. Perusahaan akan selalu berusaha untuk branding produknya melalui kemasan. Kemasan dapat mempengaruhi perilaku konsumen tentang produk tersebut misalnya dengan model kemasan yang terlihat elegant, lucu dan menarik.

\subsubsection{Media Sosial}

Media iklan yang paling banyak digunakan perusahaan adalah media sosial, semakin banyaknya aplikasi yang bermunculan sehingga membuat masyarakat lebih tertarik untuk melihat iklan dari media sosial yakni facebook, Instagram, youtube, twitter dan lain lain.

\section{Hasil dan Diskusi}

\subsection{Karakteristik Responden}

Responden yang akan mengisi kuesioner akan dipandu peneliti, kuesioner di distribusikan ke masing - masing responden dengan total 410 kuesioner untuk responden dari beberapa universitas swasta di Kepulauan Riau.

\subsection{Validitas}

\begin{tabular}{|c|c|c|}
\hline Pertanyaan & $\begin{array}{l}\text { Factor } \\
\text { Loading }\end{array}$ & Kesimpulan \\
\hline Dukungan & 0,739 & Valid \\
\hline \multicolumn{3}{|l|}{ Selebriti } \\
\hline & 0,794 & Valid \\
\hline & 0,662 & Valid \\
\hline & 0,799 & Valid \\
\hline & 0,835 & Valid \\
\hline & 0,794 & Valid \\
\hline & 0,828 & Valid \\
\hline & 0,769 & Valid \\
\hline & 0,769 & Valid \\
\hline & 0,740 & Valid \\
\hline
\end{tabular}




\begin{tabular}{lcc}
\hline Desain & 0,708 & Valid \\
Kemasan & & \\
& 0,708 & Valid \\
& 0,740 & Valid \\
& 0,750 & Valid \\
& 0,697 & Valid \\
& 0,766 & Valid \\
& 0,799 & Valid \\
& 0,780 & Valid \\
& 0,763 & Valid
\end{tabular}

Media $\quad 0,730 \quad$ Valid

Sosial

$\begin{array}{ll}0,764 & \text { Valid } \\ 0,725 & \text { Valid } \\ 0,777 & \text { Valid } \\ 0,780 & \text { Valid } \\ 0,776 & \text { Valid } \\ 0,773 & \text { Valid } \\ 0,686 & \text { Valid }\end{array}$

\subsection{Uji t}

\begin{tabular}{lll}
$\begin{array}{l}\text { Variabel } \\
\text { independen }\end{array}$ & \multicolumn{2}{l}{ Unstandardized coefficientss } \\
& B & Std.Errror \\
\hline Dukungan Selebriti & 0,238 & 0,052 \\
Desain Kemasan & 0,185 & 0,051 \\
Media sosial & 0,238 & 0,051 \\
\hline
\end{tabular}

\begin{tabular}{lll}
\hline Pertanyaan & $\begin{array}{l}\text { Factor } \\
\text { Loading }\end{array}$ & Kesimpulan \\
\hline & 0,670 & Valid \\
& 0,722 & Valid \\
Keputusan & 0,787 & Valid \\
Pembelian & & \\
& 0,761 & Valid \\
& 0,789 & Valid \\
& 0,780 & Valid \\
& 0,772 & Valid \\
& 0,735 & Valid \\
& 0,630 & Valid \\
\hline
\end{tabular}

\subsection{Uji $\mathbf{R}^{2}$}

\begin{tabular}{|c|c|c|c|}
\hline \multirow[t]{3}{*}{$\mathbf{R}$} & \multirow{3}{*}{$\begin{array}{l}\text { R } \\
\text { Squar } \\
\text { e }\end{array}$} & Adjuste & Std.Erro \\
\hline & & d $\quad \mathbf{R}$ & $r$ of the \\
\hline & & Square & estimate \\
\hline 0,504 & 0,254 & 0,249 & 0,69734 \\
\hline $\mathrm{a}$ & & & \\
\hline
\end{tabular}

\section{Kesimpulan}

Penelitian dilakukan berdasarkan semakin banyaknya selebriti yang meninggalkan dunia perfilman dan beralih ke dunia iklan lebih dengan memanfaatkan fungsi media sosial. 
Keputusan pembelian menjadi pertimbangan saat konsumen membeli produk tertentu dikarenakan membutuhkannya atau hanya sekedar ingin tau produk tersebut karena sudah dipromosikan oleh selebriti maupun followers dari akun media sosial.

Responden lebih meyakini membeli sesuatu dengan pengaruh selebriti terkait dalam promosi iklan tersebut. Hasil dari penelitian Dukungan Selebriti sangat berpengaruh Terhadap Keputusan Pembelian dikarenakan sikap, kepercayaan diri dan daya tarik meningkatkan keputusan pembelian responden dengan lebih yakin.

Dilihat dari hasil uji bahwa variabel Dukungan Selebriti, Desain Kemasan dan Media Sosial memiliki keterkaitan, Responden lebih memiliki ketertarikan ke suatu produk jika produk tersebut terlihat bagus desain kemasan atau bisa disebut unik dengan begitu secara tidak langsung responden akan memperlihatkan kemasan produk tersebut melalui akun media sosialnya seperti instagram dan facebook sehingga membuat keputusan pembelian responden yang lain untuk membelinya.

Maka disimpulkan faktor yang mempengaruhi konsumen terhadap keputusan pembelian. Pengaruh Dukungan Selebriti, Desain Kemasan, Media sosial terhadap keputusan pembelian disimpulkan berpengaruh signifikan. 
Daftar pustaka

Ahmad, N., Billoo, M., \& Lakhan, A. (2012). Effect of Product Packaging on consumer buying decision. Journal of Business Strategies, 6(2), 1-10. Retrieved from

http://search.proquest.com.ezproxy .aut.ac.nz/docview/1321689628/ful ltextPDF?accountid $=8440$

Allahawiah, S. R., \& Tarawneh, M. M. (2018). The impact of social networks in influencing the consumer purchasing decision via the internet: Analytical study in Albalqa applied university. Journal of Theoretical and Applied Information Technology, 96(24), 8109-8121.

Andrianto, N. F., Sutrasmawati, E., Manajemen, J., Ekonomi, F., Semarang, U. N., \& Artikel, I. (2016). Pengaruh Celebrity Endorser dan Brand Image pada Proses Keputusan Pembelian. Management Analysis Journal, $5(2)$, 104-109.

https://doi.org/10.15294/maj.v5i2. 8055

Anwar, R. N. (2018). Pengaruh Kepercayaan Dan Media Sosial Terhadap Keputusan Pembelian
Konsumen E-Commerce Fashion Muslim Hijup Di Jakarta. Jurnal Manajemen Bisnis Krisnadwipayana, 6(1), 75-85. https://doi.org/10.35137/jmbk.v6i1 .169

Auttarapong, D. (2012). Package design expert system based on relation between packaging and perception of customer. Procedia Engineering, 32 , 307-314. https://doi.org/10.1016/j.proeng.20 12.01 .1272

Babu, M. N. (2014). The Impact of Celebrity Endorsement on Purchase Decision of Telecom Users- A Case of Engineering Students. Global Journal of Advanced Research, 1(2), 289-305. https://doi.org/10.1016/S00086223(02)00292-0

Ghozali, I. (2001). Aplikasi Analisis Multivariate dengan program spss (II).

Hair, J. F. J., Black, W. C., Babin, B. J., \& Anderson, R. E. (2014). Multivariate Data Analysis.

Hassan, S. H., Lee, W. L., \& Peng, W. W. (2012). the Influence of Food Product 
Packaging Attributes in Purchase

Decision: a Study Among

Consumers in Penang, Malaysia.

Journal of Agribusiness Marketing,

5, 14-28. Retrieved from http://citeseerx.ist.psu.edu/viewdoc /download?doi=10.1.1.923.5825\&r $\mathrm{ep}=\mathrm{rep} 1 \&$ type $=$ pdf

Ifeanyichukwu, C. D. (2016). Effect of Celebrity Endorsements on Consumers Purchase Decision in Nigeria. International Research Journal of Management, IT \& Social Sciences, 3(9), 103. https://doi.org/10.21744/irjmis.v3i 9.261

Khatib, F. (2016). The Impact of Social Media Characteristics on Purchase Decision Empirical Study of Saudi Customers in Aseer Region. International Journal of Business and Social Science, 7(4), 41-50. https://doi.org/10.1016/j.tourman.2 012.11 .009

Mercado, M. C. (2017). Effect of Packaging Design in the Purchase Decision Process : A Comparison of Generations, 11(2), 11-26.

Nabil Iblasi, W., Bader, D. M., \& Ahmad Al-Qreini, S. (2016). The Impact of Social Media as a Marketing Tool on Purchasing Decisions (Case
Study on SAMSUNG for Electrical Home Appliances). International Journal of Managerial Studies and Research, 4(1), 14-28. Retrieved from www.arcjournals.org

Poturak, M., \& Softic, S. (2019). Influence of Social Media Content on Consumer Purchase Intention: Mediation Effect of Brand Equity. Eurasian Journal of Business and Economics, 12(23), 17-43. https://doi.org/10.17015/ejbe.2019. 023.02

Roro, D., Rahayu, R., \& Utami, C. W. (2015). THE INFLUENCE OF SOCIAL MEDIA ( INSTAGRAM

) AND PACKAGING DESIGN ON DECISION OF ROCOCO PURCHASE ( ORGANIC NATA DE COCO ), (June), 228-236.

Sugiyono. (2016). Metode penelitian Kuantitatif, Kualitatif, dan $R \& D$. Yogesh, F., \& Yesha, M. (2014). Effect of Social Media on Purchase Decision. Pacific Business Review International, 6(11), 45-51. 